\title{
Raça e Gênero no corpo docente da Universidade Federal do Pampa
}

Cristiane Barbosa SoARes, Universidade Federal do Pampa

Fabiane Ferreira da SILVA, Universidade Federal do Pampa

O artigo propõe problematizar o perfil docente da Universidade Federal do Pampa, a partir da intersecção de gênero e raça. Para tanto, adotamos como proposta metodológica a etnografia de documentos a fim de analisar os dados da universidade e os cadastrados nos currículos lattes das(os) docentes. A análise mostrou que o corpo docente apresenta-se como majoritariamente branco e com as áreas de conhecimento consideradas femininas ocupadas predominantemente por mulheres e as consideradas masculinas ocupadas por homens. Tais dados retratam a baixa representatividade de negras(os) no corpo docente da instituição e, ainda, a persistência da dicotomia de gênero nas áreas do conhecimento, o que mostra a resistência do meio acadêmico em romper com as desigualdades raciais e de gênero.

PALAVRAS-Chave: Ensino Superior. Raça. Gênero. Docência.

Interseccionalidade. 


\section{Reflexões iniciais}

Considerando a construção da sociedade brasileira, estruturada na invisibilidade e silenciamento da população negra e na política de eugenia do governo brasileiro nos anos de 1930, corroboramos com Marilena Chauí (2003, p. 5) ao afirmar que "a universidade é uma instituição social e como tal exprime de maneira determinada a estrutura e o modo de funcionamento como um todo". Assim como a universidade, a escola, tomada também como uma instância social, é imprescindível para a construção deste contexto racial e socialmente desigual.

Com "a escola pública projetada para formar o espírito da nação havia se tornado praticamente branca através de políticas adotadas na era Vargas" (CARVALHO, 2006, p. 96), e, ainda, com a destituição do pouco capital escolar que a população negra havia conquistado no pósabolição, as primeiras turmas universitárias constituídas no Brasil, nos anos de 1930, não contavam com estudantes e tão pouco com docentes negras(os). Ainda, o mesmo autor nos alerta sobre o confinamento racial do mundo acadêmico brasileiro, que de acordo com a própria história da sociedade brasileira é produto dos discursos e das políticas de branqueamento que o estado brasileiro aderiu como projeto de nação. A partir deste entendimento, não podemos desconsiderar que a sociedade brasileira foi estruturada na invisibilidade da população negra, uma vez que esta estrutura se reflete diretamente no cenário educacional brasileiro.

Diante de um contexto de iniquidades sociais criam-se estratégias de resistências, como prática emancipatória, que permitem aos grupos historicamente oprimidos a criação de estratégias para que possam transitar entre as verdades impostas e ao mesmo tempo refletir e questioná-las. Desta forma, as atuações do movimento social negro, na década de 1970, destacam-se para romper com essa lógica de desigualdade que define o funcionamento da sociedade e alertar sobre a necessidade de se discutir o racismo que estrutura a sociedade brasileira.

Ao trazer o debate sobre o racismo para a cena pública e indagar as políticas públicas e seu compromisso com a superação das desigualdades raciais, esse movimento social ressignifica e politiza a raça, dando-lhe um trato emancipatório e não inferiorizante (GOMES, 2017, p. 21).

Assim, ao ressignificar raça se "constrói novos enunciados e instrumentos teóricos, ideológicos, políticos e analíticos para explicar 
como o racismo brasileiro opera não somente na estrutura do estado, mas na vida cotidiana de suas próprias vítimas" (GOMES, 2017, p. 21). A partir desta ressignificação, raça é incorporada nas discussões políticas do Estado Brasileiro que, na década de 1990, aceita as primeiras propostas do movimento social negro como possibilidade para o campo da educação. Estas propostas para o campo da educação se concretizam somente no ano de 2003 com a criação da Lei n. 10.639/2003, que inclui obrigatoriedade da temática "História e Cultura Afro-Brasileira" no currículo da educação básica brasileira.

Além da criação da Lei 10.639/2013 o movimento social negro teve outras conquistas sociopolíticas no cenário dos debates políticoeducacionais. Destacamos a criação em março de 2003 da Secretaria Especial de Políticas de Promoção da Igualdade Racial da Presidência da República (SEPPIR), as Diretrizes Curriculares para a Educação das Relações Étnico-Raciais e o ensino de História e Cultura Afro-Brasileira e Africana instituída pelo parecer do CNE/CP 3/2004, o Estatuto da Igualdade Racial sob a Lei $\mathrm{n}^{0} 12.288 / 2010$ e a criação das políticas de cotas, sob a Lei 12.711/2012, para o ingresso da população sob os critérios de renda e pertencimento racial no ensino superior e sob a Lei $\mathrm{n}^{\mathrm{o}}$ 12.990/2014, que reserva às(aos) negras(os) $20 \%$ das vagas oferecidas nos concursos públicos. Consideramos que tais ações e legislações configuram-se em "um fenômeno que rompe radicalmente com a lógica de funcionamento do mundo acadêmico brasileiro desde sua origem no início do século passado" (CARVALHO, 2006, p. 88). Ou seja, o campo da educação superior agora se amplia para a presença de negras(os)s nos espaços acadêmicos tanto como estudantes quanto como docentes.

Perpassando este cenário, consideramos importante olhar para a universidade articulando os marcadores de gênero e raça, a fim de conhecermos os sujeitos que a constituem e sabermos se o confinamento racial do espaço acadêmico ainda persiste. Para tanto, defendemos o argumento de que conhecer o passado é fundamental para que possamos compreender o presente e entender que o ambiente acadêmico, legitimado como espaço de excelência e mérito, compactua com o racismo acadêmico. Ou seja, é preciso questionar também o ambiente no qual nos localizamos, pesquisamos e colaboramos cientificamente - a Universidade Federal do Pampa (Unipampa). Com isso, algumas questões se colocam: Qual o perfil do corpo docente da instituição? Há professoras(es) negras(os) no quadro docente? Em que áreas de 
conhecimento atuam? Assim, este ensaio teórico como primeiro movimento de pesquisa tem como objetivo delinear o perfil docente da Unipampa, problematizando as questões de gênero e raça nesta instituição.

\section{O enegrecer do espaço acadêmico}

Considerando que raça é uma construção política e social, uma categoria discursiva articulada à prática social alusiva a hierarquização social das pessoas segundo a cor da sua pele e traços fenotípicos (GOMES, 2012), podemos quantificar que a população que se autodeclara negra - incluindo pretas(os) e pardas(os) - representa $54,9 \%$ do total da população brasileira. Assim, depois da Nigéria, o Brasil abriga a segunda população negra mais numerosa do mundo e tem a desigualdade como um desafio histórico visto que a população que se autodeclara negra é a parcela que tem seu acesso aos bancos escolares limitados, as maiores taxas de desemprego, menor acesso a serviços sanitários básicos, maior vulnerabilidade em respeito às condições de moradia, menor acesso a bens duráveis e menor expectativa de vida (IPEA, 2011; IPEA e FBSP, 2018; IBGE, 2018).

No que tange a educação, o estudo Estatísticas de gênero: indicadores sociais das mulheres no Brasil (IBGE, 2018), nos mostra que no ano de 2016 as mulheres e homens brancos representavam respectivamente $23,5 \%$ e $20,7 \%$ da população entre 25 anos ou mais de idade com ensino superior completo, enquanto as mulheres negras representavam 10,4\% e os homens negros representavam apenas 7,0\% desta população. Tais índices evidenciam a baixa participação das mulheres negras e dos homens negros nos quadros acadêmicos quando confrontados com os números de mulheres e homens brancas(os). Ao mesmo tempo, os dados apontam que as mulheres, representadas em $33,9 \%$, tem mais escolarização que os homens que representam o total de $27,7 \%$ com ensino superior completo.

Ao nos referirmos à profissão docente no ensino superior, segundo os microdados divulgados pelo Instituto Nacional de Estudos e Pesquisas Educacionais Anísio Teixeira (Inep) em 2017, ano das informações públicas mais recentes, haviam o total de $392.036 \mathrm{mil}$ docentes que davam aulas em universidades públicas e particulares do Brasil, mas deste número apenas 62.239 , ou $16 \%$ do total, se autodeclararam negras(os), 45\% são mulheres e $55 \%$ homens. 
Importante ressaltar que $29,4 \%$ das(os) docentes se recusaram a declarar uma cor ou raça. Esses números nos alertam para uma desigualdade racial bem demarcada no quadro docente do ensino superior, confirmando a configuração de uma universidade estruturada e acionada a partir de um componente de confinamento racial 1 .

No entanto, além disto, os dados mostram significativa mudança quando comparados ao Censo da Educação Superior de 2010 onde as(os) docentes negras(os) ocupavam 11,5\% das vagas, perfazendo 36.535 docentes do ensino superior. Com isso, percebemos que entre o período de 2010, onde haviam 36.535 docentes negras(os), a 2017, com 62.239, o número de professoras(es) negras(os) no ensino superior cresceu 25.953, em número absoluto, o que corresponde a um aumento de 41,7\% no quadro docente ocupadas(os) por negras(os), segundo os dados do censo da educação superior desses períodos.

Os dados também nos mostram outro efeito do confinamento racial no espaço acadêmico, pois além de continuarem sendo uma minoria entre o total de professoras(es) universitárias(os), as(os) negras(os) veem a representatividade racial cair conforme aumenta o grau de escolaridade dessas(es) docentes. No mesmo período de 2010 a 2017, o número de professoras(es) com mestrado subiu de 85.655 para 115.869, sendo que as(os) negras(os) correspondiam em 20\% desse total no ano de 2010, passando para 23\% no ano de 2017. Já entre as(os) professoras(es) com doutorado, o número aumentou de 53.006 para 100.354, com a parcela representativa das(os) negras(os) crescendo de 11,4\% para 17,6\%. (INEP, 2010; 2017).

Com todos esses dados é possível evidenciar que, mesmo numericamente inferior às(aos) docentes brancas(os), o quadro docente das instituições de ensino superior começou a enegrecer-se. No entanto, é importante notar que esta mudança não se deu ao acaso, o espaço acadêmico vem sendo aos poucos ocupado por negras(os), segundo matéria da Agência Brasil,

1 Confinamento Racial é um termo elaborado por José Jorge Carvalho (2006) ao explicitar a segregação racial no meio universitário e os mecanismos que fundamentam o racismo acadêmico. Mostrando dados do número de docentes de algumas das principais universidades públicas brasileiras, evidencia a configuração racial presente no espaço acadêmico, uma vez que número de professoras(es) negras(os) nestas instituições não chega à $1 \%$ considera a classe acadêmica racialmente privilegiada e que se mantem nesse espaço sem questionar esse universo majoritariamente branco. 
A chance de ter um diploma de graduação aumentou quase quatro vezes para a população negra nas últimas décadas no Brasil. Depois de mais de 15 anos desde as primeiras experiências de ações afirmativas no ensino superior, o percentual de pretos e pardos que concluíram a graduação cresceu de 2,2\%, em 2000, para 9,3\% em 2017. (EBC, 2018, online)

Além das políticas de cotas para ingresso no ensino superior, Lei de Cotas 12.711/2012 e a Lei $\mathrm{n}^{\mathrm{o}}$ 12.990/2014, que reserva às(aos) negras(os) $20 \%$ das vagas oferecidas nos concursos públicos para provimento de cargos efetivos e empregos públicos, temos as ações afirmativas nos programas de pós-graduação, segundo Portaria de maio de 2016 - Capes/MEC, implementadas a fim de colaborar para a mudança deste cenário de desigualdade racial no ambiente acadêmico. Assim, uma vez articuladas podem ser consideradas essenciais para o enegrecer do espaço acadêmico.

Ainda, colaborando com essa mudança de cenário de desigualdade, podemos elencar outro fator de atuação, a política de expansão da educação superior. Que a partir da interiorização das universidades federais, através do Programa de Apoio à Planos de Reestruturação e Expansão das Universidades Federais (Reuni) instituído pelo Decreto $\mathrm{n}^{0}$ 6.096/2007, ampliou o acesso e a permanência na educação superior, oportunizando a abertura de vagas para professoras(es) do ensino superior público. Além disso, o Reuni é o programa responsável pela criação da Unipampa, universo desta pesquisa, na metade sul do estado do Rio Grande do Sul.

\section{Contextualizando o universo de pesquisa: olhares sobre o quadro docente da Unipampa}

A Unipampa é resultado da política de expansão das universidades federais, o Reuni. Em seus 10 anos de implantação, completados no ano de 2018, a instituição conta com 67 cursos de graduação, 34 pós-graduação lato sensu, concluídos ou em andamento, e 19 programas de pós-graduação stricto sensu em funcionamento, segundo dados divulgados pela Pró-reitoria de Planejamento e Infraestrutura (PROPLAN).

A instituição conta com 10 campi estrategicamente localizados nas fronteiras sul e oeste do Rio Grande do Sul; sendo nas cidades de 
Alegrete, Bagé, Caçapava do Sul, Dom Pedrito, Itaqui, Jaguarão, Santana do Livramento, São Borja, São Gabriel e Uruguaiana. Mesmo sendo uma instituição única, seu perfil multicampi possibilitou a cada um dos 10 campi construir características e especificidades a partir das áreas de conhecimento instauradas em seus contextos.

No seu Plano de Desenvolvimento Institucional (PDI), de 2014 2018 assume a missão de "de promover a educação superior de qualidade, com vistas à formação de sujeitos comprometidos e capacitados a atuarem em prol do desenvolvimento regional, nacional e internacional" (UNIPAMPA, 2013; p. 13). Com este anúncio do PDI, um planejamento estratégico foi traçado e estruturado a partir de quatro eixos: Excelência Acadêmica, Aperfeiçoamento Institucional, Dimensão Humana e Compromisso Social. Tais eixos especificam as ações a serem realizadas pela instituição de forma a consolidar o Perfil Institucional anunciado pelo PDI.

A criação da Universidade Federal do Pampa é marcada por intencionalidades, dentre essas o direito à educação superior pública e gratuita por parte dos grupos que historicamente estiveram à margem deste nível de ensino. Sua instalação em região geográfica marcada por baixos índices de desenvolvimento edifica a concepção de que o conhecimento produzido neste tipo de instituição é potencializador de novas perspectivas. (UNIPAMPA, 2013; p. 13).

No eixo Compromisso Social a instituição assume o compromisso com as políticas de ações afirmativas, no entanto, não especifica no planejamento deste eixo as intencionalidades do que deve ser feito no que tange as políticas de cotas raciais e/ou sociais seja para ingresso ou permanência na instituição.

Quanto ao corpo docente, o PDI trata dos critérios de seleção e contratação, os quais se dão por edital de concurso público onde "é necessário título de Doutor, conforme Lei 12.772/2012, podendo ser concursados servidores com titulação de mestre, especialista ou apenas graduado quando devidamente justificado e aprovado" (UNPAMPA, 2013, p. 47). Mas, em nenhum momento insere a possibilidade de políticas de ações afirmativas para ingresso de docentes, o que pode ser compreendido pelo ano de construção e discussão do PDI, ano de 2013, onde a Lei $\mathrm{n}^{0} 12.990 / 2014$ de reserva de vagas não havia sido aprovada até então. 
Já no ano de 2016, a Unipampa implementa a Coordenadoria de Ações Afirmativas (CAF) que, vinculada ao Gabinete da Reitoria, colabora para a manutenção das ações afirmativas no âmbito dos cursos de graduação, pós-graduação e nos editais que regulamentam as reservas de vagas em concursos da Unipampa. Desta forma a CAF deve

Garantir a equidade e a igualdade de oportunidades no acesso, na permanência, nas mobilidades e nas qualificações de discentes e servidores/as nos âmbitos do Ensino, da Pesquisa e da Extensão da Unipampa, atuando na superação das históricas desigualdades socioeconômicas, culturais e políticas na sociedade brasileira. (CAF Missão, online).

Dada a contextualização do campo desta pesquisa e objetivando apresentar o perfil docente da instituição nos apoiaremos metodologicamente na pesquisa descritiva que segundo Antonio Carlos Gil (2002, p. 42) "tem como objetivo primordial a descrição das características de determinadas populações ou fenômenos ou, então, o estabelecimento de relações entre variáveis". Como técnica de coleta de dados utilizamos a pesquisa documental, a partir dos pressupostos de Adriana Vianna (2014) que apresenta a etnografia de documentos como uma possibilidade de conduzirmos nosso olhar aos pedaços que interessam às nossas narrativas de pesquisa, neste caso os marcadores raça e gênero.

Segundo Michel Angrosino (2009, p. 30), a "etnografia é a arte e a ciência de descrever um grupo humano - suas instituições, seus comportamentos interpessoais, suas produções materiais e suas crenças", um método baseado na pesquisa de campo para revelar o retrato mais completo possível do grupo estudado. A partir desses princípios a etnografia passou a movimentar novas estratégias metodológicas que nos permite ver que cada objeto de pesquisa conta sua própria história, constrói sua narrativa e nos provocam diferentes reflexões a cada olhar.

Partindo deste entendimento, compreendemos que os materiais documentais também se constituem como peças etnográficas que contam histórias, narram vivências e, em sua forma própria, produzem como um mundo social (VIANNA, 2014). E, corroborando com Adriana Vianna, "levar a sério os documentos como peças etnográficas implica em tomá-los como construtores da realidade tanto por aquilo que produzem na situação da qual fazem parte, quanto por aquilo que conscientemente sedimentam" (VIANNA, 2014, p. 47). 
$\mathrm{Na}$ etnografia documental contamos, refletimos e delineamos, portanto, algo desse encontro arisco tenso e cheio de afetos que empreendemos com essas vidas feitas de papel, arquivo e administração. Nossas preocupações, como em qualquer etnografia, envolvem levar a sério o que nos é mostrado, o modo como essa exibição se ordena, a multiplicidade de vozes e mãos presentes na sua confecção, sua dimensão material, seu lugar em cadeia de outros documentos e ações, suas lacunas e silêncios. (VIANNA, 2014, p. 48)

Assim, os documentos formam o corpus vivo das nossas pesquisas, os quais podem se alterar e perfazer novas reflexões a cada nova leitura. Para tanto, tomamos como documentos os dados abertos do quadro docente da Unipampa e o Currículos Lattes (CL) de todas(os) as(os) docentes da instituição. $\mathrm{Na}$ análise, direcionamos os olhares aos pedaços que interessam nesta etapa a fim de delimitar o universo desta pesquisa. Levamos em consideração os sujeitos centrais - as(os) docentes; mobilizamos articulações a fim de estabelecer as categorias de gênero e raça e, assim, rastreamos sua posição - em que campus estão localizados; suas escolhas - em que área do conhecimento atuam; nas cenas específicas deste universo docente para assim construirmos o perfil do quadro docente da Unipampa em gênero e raça.

Antes de seguirmos adiante, é importante demarcarmos o que entendemos por gênero e raça, pois tais compreensões constituíram nossas leituras sobre as peças etnográficas documentais as quais nos debruçamos neste texto. Para estabelecermos a categoria de gênero a compreendemos como um ferramenta de análise do mundo social que nos ajuda a entender o trabalho da cultura sobre as diferenças biológicas/anatômicas entre machos e fêmeas da espécie humana (BONETTI, 2017). Sabemos que o nome é um dos primeiros marcadores identitários atribuído aos sujeitos, como parte da cultura, como forma de demarcar suas expressões de gênero como femininas ou masculinas. Assim, tomamos por análise a área de identificação dos CL de cada docente aliando nome e foto para a delimitação da categoria gênero.

Entendemos raça, a partir dos pressupostos de Nilma Lino Gomes (2012), como uma construção política e social, uma categoria discursiva que hierarquiza socialmente as pessoas segundo a cor da sua pele e traços fenotípicos. Para o delineamento deste marcador consideramos a heterodeclaração; que consiste em classificação do sujeito a partir de suas características fenotípicas, a cor da sua pele e as informações disponíveis nas peças etnográficas analisadas (OSÓRIO, 
2003). Nesta categoria, utilizamos as fotos das(os) docentes encontradas na análise das suas identificações no CL, e em alguns casos consultamos os perfis cadastrados em redes sociais públicas.

Importante salientar que, com base em nossos entendimentos de gênero e raça, consideramos que a heterodeclaração, assim como a análise do CL, não são suficientes para a delimitação racial e de gênero dos sujeitos, visto que tais identidades são construídas sócio e historicamente a partir de nossas experiências mais subjetivas. No entanto, as informações declaradas, no que tange gênero e raça dos sujeitos, não aparecem no CL como informações públicas, ou seja, ao realizarmos as buscas por CL não temos acesso a estas informações mesmo que os sujeitos as tenham declarado.

Dentro do universo docente é necessário perceber que "a raça e gênero tem performances importantes no âmbito da Educação Superior" (SILVA, 2010, p. 27), por isso consideramos necessário lançar olhares numa perspectiva que interseccione esses dois marcadores. Para tanto, nos apoiamos no conceito de interseccionalidade, cunhado por Kimberlé Crenshaw

A interseccionalidade é uma conceituação do problema que busca capturar as consequências estruturais e dinâmicas da interação entre dois ou mais eixos da subordinação. Ela trata especificamente da forma pela qual o racismo, o patriarcalismo, a opressão de classe e outros sistemas discriminatórios criam desigualdades básicas que estruturam as posições relativas de mulheres, raças, etnias, classes e outras. Além disso, a interseccionalidade trata da forma como ações e políticas específicas geram opressões que fluem ao longo de tais eixos, constituindo aspectos dinâmicos ou ativos do desempoderamento. (CRENSHAW, 2002, p. 177).

A partir destes entendimentos, entre o período de maio a novembro, do ano de 2018, foi realizado o levantamento total do quadro docente dos 10 campi da instituição. Nesta etapa, os dados abertos disponíveis no site da universidade e os CL foram tratados como peças etnográficas, as quais nos retrataram o perfil de gênero e raça do corpo docente da instituição. Este levantamento oportunizou a produção de dados quantitativos de cada campus, o que nos possibilitou traçar um perfil por campus de acordo com as áreas dos cursos que os compõe e o delineamento do corpo docente por gênero e raça, conforme as tabelas 1 e 2 , respectivamente. 
(Tabela 1) - Quadro geral docente por perfil de campus

\begin{tabular}{|c|c|c|c|}
\hline CAMPI & PERFIL & $\begin{array}{l}\text { CURSOS DE } \\
\text { GRADUAÇÃOO }\end{array}$ & $\begin{array}{c}\text { QUADRO } \\
\text { GERAL DOCENTE }\end{array}$ \\
\hline ALEGRETE & ENGENHARIAS & $\begin{array}{l}\text { Ciência da Computação } \\
\text { Engenharia Agrícola: } \\
\text { Engenharia Civil; } \\
\text { Engenharia de Software; } \\
\text { Engenharia de } \\
\text { Telecomunicações; } \\
\text { Engenharia Elétrica } \\
\text { Engenharia Mecânica. }\end{array}$ & 101 \\
\hline BAGÉ & $\begin{array}{l}\text { CIÊNCIAS EXATAS } \\
\text { LINGUAGENS }\end{array}$ & $\begin{array}{l}\text { Engenharia de Alimentos; } \\
\text { Engenharia de Computação; } \\
\text { Engenharia de Energia; } \\
\text { Engenharia de Produção; } \\
\text { Engenharia Química; } \\
\text { Física; } \\
\text { Letras - ling. adicionais } \\
\text { Letras - português } \\
\text { Matemática; } \\
\text { Música; } \\
\text { Química }\end{array}$ & 164 \\
\hline CAÇAPAVA DO SUL & $\begin{array}{l}\text { CIÊNCIAS EXATAS } \\
\text { E DA TERRA }\end{array}$ & $\begin{array}{l}\text { Ciências Exatas; } \\
\text { Engenharia Ambiental e } \\
\text { Sanitária; } \\
\text { Geofísica; } \\
\text { Geologia; } \\
\text { Mineração. }\end{array}$ & 65 \\
\hline DOM PEDRITO & $\begin{array}{l}\text { CIÊNCIAS AGRÁRIAS } \\
\text { EDUCAÇÃO }\end{array}$ & $\begin{array}{l}\text { Agronegócio; } \\
\text { Ciências da Natureza; } \\
\text { Educação no Campo; } \\
\text { Enologia; Zootecnia. }\end{array}$ & 66 \\
\hline ITAQUI & $\begin{array}{l}\text { CIÊNCIAS AGRÁRIAS } \\
\text { EXATAS E NUTRIÇÃO }\end{array}$ & $\begin{array}{l}\text { Agronomia; } \\
\text { Ciência e Tecnologia de } \\
\text { Alimentos; } \\
\text { Engenharia de } \\
\text { Agrimensura; } \\
\text { Interdisciplinar em } \\
\text { Ciência e Tecnologia; } \\
\text { Matemática; } \\
\text { Nutrição. }\end{array}$ & 85 \\
\hline JAGUARÃO & $\begin{array}{l}\text { CIÊNCIAS HUMANAS } \\
\text { LINGUAGENS }\end{array}$ & $\begin{array}{l}\text { Gestão de Turismo; } \\
\text { História; } \\
\text { Letras - Português/EaD } \\
\text { Letras - Port./Espanhol } \\
\text { Pedagogia - UAB } \\
\text { Pedagogia } \\
\text { Produção e Política } \\
\text { Cultural }\end{array}$ & 70 \\
\hline $\begin{array}{l}\text { SANTANA DO } \\
\text { LIVRAMENTO }\end{array}$ & $\begin{array}{l}\text { CIÊNCIAS JURÍCAS } \\
\text { ECONÔMICAS }\end{array}$ & $\begin{array}{l}\text { Administração; } \\
\text { Adm. Pública - UAB } \\
\text { Ciências Econômicas; } \\
\text { Direito; } \\
\text { Gestão Pública; } \\
\text { Relações Internacionais }\end{array}$ & 67 \\
\hline
\end{tabular}




\begin{tabular}{|c|c|c|c|}
\hline SÃO BORJA & $\begin{array}{c}\text { CIÊNCIAS HUMANAS } \\
\text { CIÊNCIAS SOCIAIS }\end{array}$ & $\begin{array}{l}\text { Ciências Humanas; } \\
\text { Ciências Sociais } \\
\text { Ciência Política; } \\
\text { Com. Social - P.P } \\
\text { Direito; } \\
\text { Geografia - UAB } \\
\text { Jornalismo } \\
\text { Relações Públicas; } \\
\text { Serviço Social. }\end{array}$ & 71 \\
\hline SÃO GABRIEL & CIÊNCIAS BIOLÓGICAS & $\begin{array}{l}\text { Biotecnologia; } \\
\text { Ciências Biológicas - Bal.; } \\
\text { Ciências Biológicas - Lic.; } \\
\text { Engenharia Florestal; } \\
\text { Gestão Ambiental }\end{array}$ & 61 \\
\hline URUGUAIANA & $\begin{array}{l}\text { CIÊNCIAS DA SAÚDE } \\
\text { EDUCAÇÃOO }\end{array}$ & $\begin{array}{l}\text { Aquicultura; } \\
\text { Ciências da Natureza; } \\
\text { Educação Física; } \\
\text { Enfermagem; } \\
\text { Farmácia; } \\
\text { Fisioterapia; } \\
\text { Medicina; } \\
\text { Medicina Veterinária. }\end{array}$ & 172 \\
\hline TOTAL & & 67 & 922 \\
\hline
\end{tabular}

Fonte: dados abertos da Unipampa/Pesquisa Direta (2018) Produção das próprias autoras.

(Tabela 2) - Quadro geral docente com recorte de gênero e raça

\begin{tabular}{|c|c|c|c|c|c|}
\hline CAMPI & $\begin{array}{c}\text { TOTAL } \\
\text { DOCENTE }\end{array}$ & HOMENS & MULHERES & $\begin{array}{l}\text { HOMENS } \\
\text { NEGROS }\end{array}$ & $\begin{array}{c}\text { MULHERES } \\
\text { NEGRAS }\end{array}$ \\
\hline ALEGRETE & 101 & 81 & 20 & 3 & 1 \\
\hline BAGÉ & 164 & 86 & 78 & 7 & 2 \\
\hline $\begin{array}{l}\text { CAÇAPAVA DO } \\
\text { SUL }\end{array}$ & 65 & 41 & 24 & 1 & 0 \\
\hline DOM PEDRITO & 66 & 29 & 37 & 1 & 2 \\
\hline ITAQUI & 85 & 45 & 40 & 1 & 2 \\
\hline JAGUARÃO & 70 & 23 & 47 & 2 & 7 \\
\hline $\begin{array}{l}\text { SANTANA DO } \\
\text { LIVRAMENTO }\end{array}$ & 67 & 34 & 33 & 3 & 0 \\
\hline SÃO BORJA & 71 & 32 & 39 & 2 & 5 \\
\hline SÃO GABRIEL & 61 & 37 & 24 & 1 & 0 \\
\hline URUGUAIANA & 172 & 72 & 100 & 1 & 5 \\
\hline TOTAL & 922 & 480 & 442 & 22 & 24 \\
\hline
\end{tabular}

Fonte: dados abertos da Unipampa e Plataforma Lattes/Pesquisa Direta (2018) Produção das próprias autoras. 
Analisando o quadro docente em sua totalidade, conforme a tabela 2, observamos que, das(os) 922 professoras(es), 876 são brancas(os) e 46 são negras(os) o que equivale dizer que 95\% do quadro docente da Unipampa é ocupado por professoras(es) brancas(os). Esses dados comparados com os estudos de Carvalho (2006); que aponta que das(os) 18.400 professoras(es) das principais universidades do país, apenas 70 eram negras(os), ou seja, 99,6\% de docentes brancas(os) e apenas 0,4\% de docentes negro(a)s. Já o estudo de Gonçalves e Ambar (2015), relata que no contexto da Universidade Federal de São Paulo, com mais de 200 professoras(es), apenas três são negras(os), mostrando o quanto o espaço acadêmico constitui-se como hegemonicamente branco, um retrato que persiste no contexto universitário brasileiro.

Tais números também corroboram com os dados nacionais apresentados pelo Inep (2017), uma vez que as vagas ocupadas por professoras(es) negras(os) de nível superior chegam a apenas 16\%. Como podemos constatar, o corpo docente do ensino superior continua predominantemente branco o que é um importante indicativo da resistência do meio acadêmico em romper com as desigualdades raciais, ou seja, continuamos imersos no confinamento racial do mundo acadêmico.

Ao explicitar esses dados, não podemos desconsiderar a configuração racial presente neste quadro docente, uma vez que,

Podemos falar aqui, para não esvaziar a palavra "racismo", de uma situação de confinamento racial vivida por nós, docentes das universidades públicas brasileiras. Se não somos diretamente responsáveis por essa exclusão, nem nos sentimos coniventes com a sua reprodução, então admitamos, pelo menos, para iniciar uma reflexão crítica, que temos sido forçados a desenvolver nossas atividades dentro de um regime de confinamento racial que herdamos das gerações passadas de acadêmicos. (CARVALHO, 2006, p. 92).

Nesta perspectiva e como nos mostram os dados, mesmo num contexto pós-ações afirmativas o confinamento racial persiste, mas isso não diz respeito somente ao corpo docente negro, que enfrenta os mecanismos de silenciamento, invisibilidades e barreiras institucionais, também diz respeito às(aos) brancas(os), que em um país composto por $54,9 \%$ de negras(os), continuam sendo a maioria em espaços de poder e no meio acadêmico e não se questionam sobre isso. Como afirma Joselina da Silva e Maria Simone Euclides (2018, p. 52), espaços 
públicos e/ou privados "não estão imunes à lógica de diferenciação e desigualdades entre os indivíduos. Trata-se de ambientes onde a hierarquização e o distanciamento na espacialização passam a ser vistos de forma banalizada e natural". Com isso, podemos inferir que este confinamento racial não ocorre somente no que tange a interlocução acadêmica, mas também à produção de conhecimento que acaba por ser marcada e legitimamente branca.

Ainda, a partir da tabela 2, podemos problematizar como a intersecção de gênero e raça produzidas, num contexto social de opressões e oportunidades, posicionam as(os) professoras(es) de ensino superior. Além disso, temos poucas produções teóricas que consideram em sua análise a articulação desses marcadores, como afirma Brito (2017, p. 1-2) "estudos realizados sobre mulheres e educação no Brasil pouco se preocupam em incluir a variável raça nos apontamentos" e complementa que,

As pesquisas indicam que os estudos sobre gênero têm avançado sistematicamente, nas últimas décadas do século $\mathrm{XX}$, principalmente nos Estados Unidos e contribuído significativamente para compreensão dos múltiplos eixos da opressão feminina, porém o recorte enfatizando raça, etnia e classe, especialmente no que cerne as experiências vivenciadas pelos negros e negras no Brasil, não tem priorizado as diferenças raciais. $\mathrm{O}$ que faz dos estudos realizados serem abordados numa perspectiva parcial. (BRITO, 2017, p. 2).

Com isso, a tabela 2, que apresenta o delineamento do quadro docente em gênero e raça, mostra que $46 \%$ das vagas docentes são ocupadas por mulheres. Esses dados da Unipampa corroboram com o Censo da Educação Superior (INEP, 2017) o qual mostra que as mulheres ocupam aproximadamente $45 \%$ das vagas docentes nas universidades brasileiras. Entretanto, destas, apenas 5,4\% são ocupadas por professoras negras. Em relação à presença masculina, o mesmo quadro é representado por um total de $54 \%$ de homens, onde apenas 4,6\% são professores negros. Analisando tais dados numa perspectiva parcial, sem considerar a intersecção dos marcadores de gênero e raça, podemos considerar que existe um equilíbrio entre homens e mulheres no quadro de docentes, contudo ao lançarmos mão de tal perspectiva percebemos que o equilíbrio existente em gênero mascara a desigualdade racial presente no contexto da docência no ensino superior.

Apoiadas em Judith Butler (2015, p. 21), compreendemos que a noção de gênero não se constitui de maneira consistente e coerente, ela 
"estabelece intersecções com modalidades raciais, classistas, étnicas, sexuais e regionais de identidades discursivamente constituídas". Partindo deste entendimento, ao analisarmos o quadro docente percebemos que as mulheres estão inseridas na docência superior, entretanto, a questão que se coloca sobre este universo é: quem são essas mulheres? Para satisfazer este questionamento devemos considerar a intersecção dos marcadores de gênero e raça, visto que a categoria mulheres não é uma identidade comum à todas as mulheres. E, ao mesmo tempo, precisamos enfatizar a necessidade deste olhar na perspectiva interseccional visto que existe um equilíbrio no número de mulheres e homens, no entanto, ao estabelecermos o marcador racial o universo docente mostra-se majoritariamente branco composto por $95 \%$ de docentes brancas(os), como discutido anteriormente.

As(os) professoras(es) negras(os) representam 5\% do universo docente da Unipampa, demarcando este cenário a partir da intersecção dos marcadores de gênero e raça percebemos a pequena porcentagem de diferença entre o número de professoras negras $(5,4 \%)$ e de professores negros (4,6\%). No entanto, analisando os lugares ocupados por essas(es) docentes percebemos que os cursos com maior status social, e considerados masculinos, ainda permanecem como áreas predominadas por homens, apesar da existência e resistência das mulheres (SILVA, 2012). De acordo com as tabelas 1 e 2, percebemos que dos 22 professores negros da Unipampa, 18 estão presentes em maior proporção nos campi com este perfil. Para ilustrar destacamos que no campus Alegrete, com cursos das áreas das Engenharias, há 3 professores negros; em Bagé, campus com cursos das áreas de Ciências Exatas e Linguagens, tem 7 professores negros; e em Santana do Livramento, com cursos das áreas das Ciências Jurídicas e Econômicas, há 3 professores negros. Já das 24 mulheres negras, 17 localizam-se nos campi com perfil como o do campus de Jaguarão (7), com cursos das áreas de Ciências Humanas e Linguagens; São Borja (5), com cursos nas áreas de Ciências Humanas e Ciências Sociais e em Uruguaiana (5), com cursos voltados para as áreas das Ciências da Saúde e Educação.

A partir desta leitura e estabelecendo conexões com o estudo de Angela Ernestina Cardoso de Brito (2017), que tange as pós-políticas afro-reparatórias sobre o processo de inserção das mulheres negras na docência do ensino superior na Universidade Federal da Bahia, podemos compor uma nova questão de análise, mesmo com a presença numérica superior das mulheres negras, os homens negros estão mais presentes 
nos cursos considerados masculinos. Em seu estudo Brito (2017) confirma que os homens negros estão presentes em maior número nas áreas do Direito (66\%), enquanto as mulheres negras estão presentes em áreas das Ciências Humanas e Ciências Sociais (73\%). Seguindo esses rastros, podemos constatar que há uma divisão de gênero e raça por área do conhecimento o que se acentua assim que tais marcadores são interseccionados.

Com isso, percebemos as operações das relações de gênero ainda em funcionamento em determinadas áreas do conhecimento. No caso do quadro docente geral da Unipampa nota-se esta polarização, ou seja, observa-se que as maiores taxas de participação masculina estão presentes nas áreas das Engenharias, seguida das Ciências Exatas, Ciências Jurídicas e Econômicas. Ao explicitarem a masculinização dessas áreas, Melo, Lastres e Marques (2004, p. 86) dizem que "isso está intimamente ligado à questão da engenharia ser um saber técnico historicamente dominado por homens”. O que nos leva a inferir que a demarcação dessas áreas como masculinas pode ser compreendida como efeito das relações de gênero historicamente construídas e legitimadas socialmente.

Consequentemente há, também, uma naturalização de áreas tidas como femininas, que com base em uma suposta "natureza delicada e sensível", a mulher foi colocada em uma posição culturalmente inferior ao homem e "as funções que lhe conviriam seriam aquelas que sugerem o prolongamento das funções domésticas - ensino, cuidado e serviço" (BELTRÃO; TEIXEIRA, 2005, p. 144). Uma vez enraizadas no imaginário social, essas convenções de gênero² tradicionais demarcaram as áreas consideradas femininas e, assim, perpassam os cursos com tais características. Podemos perceber esta operação das convenções de gênero nas áreas do conhecimento a partir das presenças acentuadas de docentes mulheres no campus de Jaguarão, com cursos das áreas das Ciências Humanas e Linguagens, que com $67 \%$ de mulheres tem o maior contingente de mulheres negras (15\%); e o campus de Uruguaiana, com cursos do campo da educação e saúde, que com $58 \%$ de docentes mulheres tem a terceira maior concentração de professoras negras (5\%).

\footnotetext{
2 Entendemos como Convenções de Gênero o "conjunto de valores e ideais relativos ao imaginário sexual disponíveis na cultura e compartilhados, a partir dos quais os seres sociais pautam as suas ações e concepções de mundo, reproduzem e recriam estas mesmas convenções e as suas práticas" (BONETTI, 2011, online).
} 
Esses dados nos alertam para uma desigualdade de gênero e raça existente e bem marcada no universo científico hegemonicamente branco e, com isso, nos mostram que as diferenças existentes entre as convenções de gênero socialmente atribuídas às mulheres e aos homens também estão presentes nas diversas áreas do conhecimento. Considerando os marcadores de gênero e raça presentes nos achados desta pesquisa, é possível constatar que o campo científico é fortemente marcado pela imbricação do sexismo e racismo e ainda permeado pela falsa ideia de que fazer ciência é um privilégio branco.

\section{Pensares conclusivos}

a representatividade é vital sem ela a borboleta rodeada por um grupo de mariposas incapaz de ver a si mesma vai continuar tentando ser mariposa

Rupi Kaur (2018, p. 239)

Diante dos achados desta pesquisa é essencial falarmos de representatividade, visto que não há representação significativa de professoras(es) negras(os) no corpo docente do ensino superior e, mesmo com a presença das mulheres em muitas áreas, essa representação não ultrapassa a barreira do gênero delimitada pelas áreas do conhecimento consideradas masculinas. A representatividade nesses espaços, historicamente negados às mulheres e negras(os), é essencial para o fortalecimento de identidades raciais e de gênero, pois enxergarse e encontrar seus pares em espaços que historicamente não nos era permitido é um importante caminho para a emancipação e resistência contra o racismo e sexismo presentes no contexto acadêmico.

Percorrendo o caminho de invisibilidade de negras(os) no campo educacional brasileiro e compreendendo a estruturação da sociedade, percebemos que o fenômeno de confinamento racial explicita-se diante do quadro docente da Unipampa. Considerando as políticas afroreparatórias e a implementação de uma universidade pública no interior do estado do Rio Grande do Sul o perfil docente que a Unipampa apresenta não difere das demais universidades dos grandes centros do país, ou seja, quadro docente branco com predominância masculina em áreas do conhecimento consideradas masculinas e predominância feminina em áreas consideradas femininas. 
Ainda que se possa observar uma ampliação de professoras(es) negras(os) no ensino superior, não podemos deixar de problematizar que o espaço acadêmico é hegemonicamente branco, com isso, legitima discursos e produz conhecimentos alicerçados em uma estrutura que segrega os sujeitos negros e confina seus saberes. Os dados apresentados nesta pesquisa subsidiam outras questões que necessitam de investigação e problematização, assim como alertam sobre a necessidade de se repensar a intencionalidade das cotas para concursos públicos, visto que os números apresentados não compactuam com as políticas de ações afirmativas, tão pouco com os objetivos do PDI da universidade.

O que nos remete a pensar: para além das políticas afroreparatórias, que estratégias seriam possíveis para o rompimento deste contexto acadêmico que ainda segrega racialmente? Por que persiste a masculinização e feminilização das áreas de conhecimento? Quem sabe possamos iniciar admitindo a existência de mecanismos de confinamento racial que estruturam esse contexto, descortinando o sexismo e o racismo deste universo acadêmico para assim ampliarmos as discussões das políticas afro-reparatórias que garantam além de ingresso e permanência, mas que possibilitem o sucesso na graduação e na pósgraduação.

Destacamos que estes achados nos mostram mais do que a ausência de professoras(es) negras(os) no ensino superior, "trata-se de uma ausência reificada pelos órgãos públicos e, de certa forma não questionada e problematizada" (SILVA; EUCLIDES, 2018, p. 54). Com isso, ressaltamos a importância da perspectiva da interseccionalidade ao considerarmos a articulação dos marcadores de gênero e raça para os olhares desta pesquisa, uma vez que os dados encontrados no quadro docente revelam um perfil hegemonicamente branco e uma polarização das áreas do conhecimento.

Com isso, salientamos a necessidade de produção de dados que colaborem para compreensão e problematização deste cenário, pois na realização desta pesquisa nos deparamos com a falta de dados gerais com o recorte de raça e gênero articulados, com a inexistência de qualquer recorte racial e/ou de gênero nos quadros docentes da instituição, autodeclaração racial não pública no CL, poucas produções teóricas sobre a negras(os) na docência superior pública, entre outras questões. Destarte, ressaltamos a necessidade de reconfiguração dos quadros docentes das instituições para que delimitem quem são as(os) docentes que constroem e colaboraram com a produção de 
conhecimento e, assim, mostrem as presenças negras no seu corpo docente.

\section{Referências}

ANGROSINO, M. Etnografia e observação participante. Coleção Pesquisa qualitativa. Porto Alegre: Artmed, 2009.

BELTRÃO, K. I.; TEXEIRA, M. Cor e gênero na seletividade das carreiras universitárias. In. SOARES, et al (orgs). Os mecanismos de descriminação racial nas escolas brasileiras. Rio de Janeiro: Ipea, 2005. p. $51-201$.

BONETTI, A. de L. Gênero, poder e feminismos: as arapiracas pernambucanas e os sentidos de gênero da política feminista. Labrys, julho/dez. 2011. Disponível em: http://www.labrys.net.br/labrys20/ brasil/aline.htm. Acesso em: 10 mar. 2018.

- Marcadores da diferença, interseccionalidades e a produção de alteridades nos processos educativos e de socialização. Projeto de pesquisa - PROPI, Universidade Federal do Pampa, 2017.

BUTLER, J. Problemas de gênero: feminismo e subversão da identidade. Coleção Sujeito \& História. 8a ed. Rio de Janeiro: Civilização Brasileira, 2015.

BRITO, A. E. C.de. Professoras negras na Universidade Federal da Bahia-UFBA: cor, status e desempenho. Seminário Internacional Fazendo Gênero 11 \& 13th Women's Worlds Congress (Anais Eletrônicos), Florianópolis, 2017.

CAF - Coordenadoria de Ações Afirmativas da Unipampa. Missão. Universidade Federal do Pampa, Online. Disponível em: http:// porteiras.s.unipampa.edu.br/caf/ Acesso em: 10 jan. 2019.

CARVALHO, J. J. de. O Confinamento racial do mundo acadêmico brasileiro. Revista USP. São Paulo, n.68, p. 88-103, dezembro/fevereiro 2005-2006.

CHAUI, M. A universidade pública sob nova perspectiva. Revista Brasileira de Educação. n. 24 - p. 5-15. Set /Out /Nov /Dez 2003. 
CRENSHAW, K. Documento para o Encontro de Especialistas em Aspectos da Discriminação Racial Relativos ao Gênero. Revista Estudos Feministas, Florianópolis, n. 10, p. 171-188, 2002.

EBC. (Agência Brasil). Cotas foram revolução silenciosa no Brasil. 2018. Disponível em: http://agenciabrasil.ebc.com.br/educacao/noticia/ 2018-05/cotas-foram-revolucao-silenciosa-no-brasil-afirma-especialista Acesso em: 30 abr. 2019.

GIL, A. C. Como elaborar projetos de pesquisa. 4.ed. São Paulo: Atlas, 2002.

GONÇALVES, R.; AMBAR, G. A questão racial, a universidade e a (in)consciência negra. Lutas Sociais, São Paulo, vol.19 n.34, p.202-213, jan./jun. 2015 .

GOMES, N. L. Movimento negro e educação: ressignificando e politizando a raça. Educação \& Sociedade, Campinas, v. 33, n. 120, p. 727-744, jul.-set. 2012.

. O Movimento Negro educador: saberes construídos nas lutas por emancipação. 1. ed. Petrópolis, RJ: Vozes, 2017.

IBGE, Instituto Brasileiro de Geografia e Estatística. Estatística de Gênero: indicadores sociais das mulheres no Brasil. Estudos e pesquisas, n. 38. Brasília: IBGE, 2018.

IPEA, Instituto de Pesquisa Econômica Aplicada (et al.). Retrato das desigualdades de gênero e raça. 4. ed. - Brasília: Ipea, 2011.

IPEA; FBSP.(et. al.) Atlas da violência 2018. Brasília: Ipea,2018. Disponível em: http://www.ipea.gov.br/portal/images/stories/PDFs/ relatorio institucional/180604 atlas da violencia 2018.pdf. Acesso em: 12 dez. 2018.

KAUR, R. O que o sol faz com as flores. São Paulo: Planeta Brasil, 2018.

MELO, H. P. de. LASTRES, H. M. M. MARQUES, T. C. de N. Gênero no Sistema de Ciência, Tecnologia e Inovação no Brasil. Revista Gênero, vol. 4, n. 2, p. 73-94. Niterói, RJ: 2004.

OSÓRIO, R. G. O sistema classificatório de "cor e raça" do IBGE. Rio de Janeiro: Ipea, 2003. 50 p. (Texto para Discussão, n. 996). 
SILVA, F. F. da. Mulheres na Ciência: vozes, tempos, lugares e trajetórias. Tese (Doutorado em Educação em Ciências: Química da Vida e Saúde) - Programa de Pós-Graduação em Educação em Ciências: Química da Vida e Saúde, Universidade Federal do Rio Grande, Rio Grande, 2012.

SILVA, J. da. EUCLIDES, M. S. Falando de gênero, raça e educação: trajetórias de professoras doutoras negras de universidades públicas dos estados do Ceará e do Rio de Janeiro (Brasil). Educar em Revista. Curitiba, Brasil, v. 34, n. 70, p. 51 - 66. jul/ago. 2018.

SILVA, J. da. Doutoras professoras negras: o que nos dizem os indicadores oficiais. Perspectiva, Florianópolis, v. 28, n. 1, 19-36, jan/ jun. 2010.

UNIPAMPA, Plano de Desenvolvimento Institucional 2014 - 2018. Bagé: Universidade Federal do Pampa, 2013.

VIANNA, A. Etnografando documentos: uma antropóloga em meio a processos judiciais. In. CASTILHO, Sergio Ricardo R.; LIMA, Antonio Carlos de S.; TEIXEIRA, Carla Costa. (orgs). Antropologia das práticas de poder: reflexões etnográficas entre burocratas, elites e corporações. Rio de Janeiro: Contra Capa, 2014. p. 43-70. 


\section{Race and Gender in the teaching staff of the Federal University of Pampa}

ABSTRACT: The article proposes to problematize the teacher profile of the Federal University of Pampa, from the intersection of gender and race. For that, we adopted as a methodological proposal the ethnography of documents in order to analyze university data and those registered in the lattes curriculum of the teachers. The analysis showed that the faculty is mostly white and with areas of knowledge considered female occupied predominantly by and women areas considered masculine occupied by men. These data portray the low representativeness of black in the of the institution and also the persistence of the gender dichotomy in the areas of knowledge, which shows the resistance of the academic environment to break with racial and gender inequalities.

KEYWORDS: Higher education. Race. Gender. Teaching. Intersectionality.

\section{Raza y Género en lo cuerpo docente de la Universidad Federal de Pampa}

RESUMEN: El artículo propone problematizar el perfil del docente de la Universidad Federal de Pampa, desde la intersección de género y raza. Para ello, adoptamos como propuesta metodológica la etnografía de los documentos para analizar los datos universitarios y los registrados en el currículum de los docentes. El análisis mostró que la facultad es principalmente blanca y con áreas de conocimiento consideradas femeninas ocupadas predominantemente por mujeres y areas considerados masculinas ocupados por hombres. Estos datos muestran la baja representatividad negra en la facultad de la institución y también la persistencia de la dicotomía de género en las áreas de conocimiento, lo que muestra la resistencia del entorno académico a romper con las desigualdades raciales y de género.

PAlabras Clave: Enseñanza superior. Raza. Género. Docencia. Interseccionalidad. 
Cristiane Barbosa SOARES

Professora de Ciências na rede municipal de educação da cidade de Uruguaiana/RS. Licenciada em Ciências da Natureza. Especialista em Educação em Ciências. Estudante de Mestrado no Programa de Pós-Graduação em Educação em Ciências: Química da Vida e Saúde da UNIPAMPA, campus Uruguaiana (2018).

Pesquisadora do Grupo de Pesquisa TUNA - Gênero, Educação e Diferença da

UNIPAMPA.

\section{Fabiane Ferreira da SILVA}

Doutora em Educação em Ciências pela Universidade Federal do Rio Grande (2012). Professora do Curso de Ciências da Natureza - Licenciatura e do PPG em Educação em Ciências, na Universidade Federal do Pampa, campus Uruguaiana. Integrante do Grupo de Pesquisa Tuna - Gênero, Educação e Diferença da UNIPAMPA. Integrante do Grupo de Pesquisa Sexualidade e Escola da FURG.

Recebido em: 04/10/2019

Aprovado em: 18/12/2019 